\title{
Practical evaluation of post-prostatectomy incontinence
}

\author{
Sidney B. Radomski, MD, FRCSC \\ Professor of Surgery (Urology), University of Toronto, and Director of the Urodynamics Laboratory, Toronto Western Hospital-University Health Network, Toronto, ON
}

Cite as: Can Urol Assoc J 2013;7(9-10):S186-8. http://dx.doi.org/10.5489/cuaj.1620

Published online October $9,2013$.

\section{Abstract}

For patients undergoing radical prostatectomy, urinary incontinence is not an uncommon postoperative complication. For some, it can resolve over time, while in others the condition persists and requires medical and/or surgical intervention. This summary provides a review of the recommended evaluations to perform in this setting.

ncontinence is one of the most significant complications of a radical prostatectomy (RP). Rates reported after RP range from $2 \%$ to $57 \%$ depending on the definition used. ${ }^{1-5}$ This summary will provide an overview of the evidence-based evaluation of incontinence in RP patients.

\section{Causes of post-RP incontinence}

Although incontinence may be present before RP (reported rates up to $21 \%),{ }^{6-9}$ preoperative incontinence is likely due to urge incontinence rather than stress incontinence.

The most common causes of incontinence post RP are damage to the distal urethral sphincter through direct injury, or injury to the nerve supply or supporting structures. ${ }^{10}$ While bladder dysfunction can also be present in $26 \%$ to $46 \%$ of patients postoperatively, it is rarely the sole cause of incontinence in this setting. ${ }^{11-16}$

Radiation can also be a contributing factor with respect to postoperative incontinence. Among patients who undergo RP after failed radiation therapy, the incidence of urinary incontinence has been reported to be as high as $44 \% .{ }^{17}$ Reported rates of incontinence after radiation and high-intensity focused ultrasound alone are $6.6 \%$ to $23 \%$ and $0.5 \%$ to $15.4 \%$, respectively. ${ }^{18-20}$

Unpublished data from the Toronto University Health Network demonstrate that, among patients who underwent radiation therapy after RP, the incidence of urinary incontinence was not dependent on the timing of the radiation. Furthermore, those who underwent early radiation (up to six months after surgery: mean 3.6 months) and those who underwent late radiation (after six months: mean
30.1 months) had similar rates of incontinence after the radiation therapy (early: $24.5 \%$; late: $23.3 \%$ ).

\section{Evidence-based evaluation}

All of the recommended evaluations listed below are based on a review of the literature conducted by Herschorn and colleagues as part of the Fourth International Consultation on Incontinence Committee on Surgical Treatment of Urinary Incontinence in Men. ${ }^{21}$ Table 1 provides a summary of the recommendations, with the levels of evidence and grade of recommendation shown for each.

History can provide a great deal of important information in the work-up of the post-RP patient with urinary incontinence. The critical factors to include are age, radiation history, date of surgery, type of surgery (nerve sparing vs. non-nerve sparing) and type of leakage (urge vs. stress; enuresis suggests urge). Other critical factors include time of day and degree of leakage (number of pads), fluid, caffeine and alcohol intake, medications, and other medical conditions

The physical examination typically does not provide a great deal of information, although meatal stenosis, phimosis and retention can be identified. A stress test (both cough and valsalva, as they can produce different results) should be performed with a full bladder and the patient upright.

Voiding diaries can be very helpful; they should capture intake, output, number of voids and leaks, and timing of each. There is no concrete evidence to recommend any particular duration of diary keeping, although four to seven days is reasonable. ${ }^{22,23} \mathrm{Pad}$ testing provides more direct evidence of incontinence than the diary. While a 24-hour test is the most accurate, practical limitations most often mean that a one-hour test is the one used. ${ }^{21,24}$ The interpretation of a one-hour test is: 0 to $1 \mathrm{~g}=$ normal/dry; 2 to $50 \mathrm{~g}=$ mild leakage; $>50$ grams = significant leakage.

Laboratory investigations are particularly important when renal failure, polyuria or diabetes is suspected. The key tests to order are blood urea nitrogen, creatinine and glucose. Urine culture and sensitivity, and urinalysis are also simple to do and can be helpful.

Formal imaging of the upper and lower urinary tract is usually not needed or warranted, but a bladder scan post-void residual is helpful, easy to do and readily available to most urologists. 


\begin{tabular}{lcc}
\hline $\begin{array}{l}\text { Table 1. Recommended evaluations of the incontinent } \\
\text { patient prior to surgical therapy } \\
\text { Level(s) of } \\
\text { evidence }\end{array}$ & $\begin{array}{c}\text { Grade of } \\
\text { recommendation }\end{array}$ \\
\hline Evaluation & $1-2$ & $\mathrm{~A}$ \\
\hline $\begin{array}{l}\text { History } \\
\text { Physical examination }\end{array}$ & $1-2$ & $\mathrm{~A}$ \\
$\begin{array}{l}\text { Urinalysis, urine } \\
\text { culture }\end{array}$ & $1-2$ & $\mathrm{~A}$ \\
$\begin{array}{l}\text { Bladder scan PVR } \\
\text { Voiding diary (2-7 } \\
\text { days) }\end{array}$ & $1-2$ & $\mathrm{~A}$ \\
$\begin{array}{l}\text { Pad test } \\
\text { Cystoscopy and } \\
\text { imaging } \\
\text { Multichannel UDS }\end{array}$ & $1-2$ & $\mathrm{~B}$ \\
$\begin{array}{l}\text { BUN, creatinine, } \\
\text { glucose }\end{array}$ & $1-2$ & $\mathrm{~B}$ \\
& $2-3$ & $\mathrm{~B}$ \\
\hline PVR: post-void residual volume; UDS: urodynamic; BUN: blood urea nitrogen. \\
\hline
\end{tabular}

There is little hard evidence for or against the use of cystoscopy in this setting. It can be useful to assess for bladder neck contracture, urethral stricture and abnormalities of the bladder itself (e.g., diverticulum, stones, staples).

The Fourth International Consultation on Incontinence Committee on Surgical Treatment of Urinary Incontinence in Men recommended urodynamic testing prior to invasive therapy to characterize the underlying pathophysiology. ${ }^{21}$ With respect to the type of test, multichannel is considered to be superior to cystometrogram, as it can identify detrusor overactivity (DO) and poor compliance. Limited access to this type of testing may, however, limit its use in Canada. Video/fluoroscopy with the urodynamics may be considered to assess reflux, the bladder neck and urethra. Urodynamics with invasive pressure-flow studies are still the gold standard to rule out bladder outlet obstruction accompanied by DO, which can cause leakage. ${ }^{25}$

There is also evidence from other urologic surgery settings that argues against using urodynamic testing prior to RP. Theil and colleagues found no evidence that patients with DO, low first sensation filling, decreased compliance or low bladder capacity had worse outcomes after artificial urinary sphincter (AUS) insertion in 86 men than those who did not have urodynamics. ${ }^{26}$ Trigo-Rocha and colleagues also reported that preoperative urodynamic findings such as DO, impaired detrusor contraction, low valsalva leak point pressure, bladder outlet obstruction and mildly reduced compliance did not lead to a bad outcome after AUS implantation. ${ }^{27}$

If one decides to do urodynamic testing after RP, there is some guidance about appropriate timing. Evidence shows that there is continued recovery of continence up to 24 months post RP $(95.2 \%$ at 12 months, $98.5 \%$ at 24 months in one study). ${ }^{28}$ Other researchers have reported a plateau at 12 months. ${ }^{29,30}$ It is reasonable, therefore, to perform post-RP urodynamics at one year.

\section{Conclusions}

Urinary incontinence is not an uncommon complication following RP. Evidence-based guidance is available to help direct investigations and make decisions about management for patients with these symptoms.

Competing interests: This article is part of a CUAI supplement sponsored by Astellas Pharma Canada, Inc. Dr. Radomski is an ongoing paid consultant with Allergan, Astellas, Eli Lilly, Merus Labs, Pfizer, and Watson. She has also received speaker fees, educational grants, and/or travel assistance from Allergan, Astellas, Eli ilily, and Pfizer within the last two years.

\section{References}

1. Goluboff ET, Saidi JA, Maser S, et al. Urinary continence after radical prostatectomy: the Columbia experience. J Urol 1998;159:1276-80. htrp://dx.doi.org/10.1016/S0022-5347(01)63580-8

2. Gray M, Petroni GR, Theodorescu D. Urinary function after radical prostatectomy: a comparison of the retropubic and perineal approaches. Urology 1999;53:881-90. http://dx.doi.org/10.1016/500904295(99)00071-0

3. Walsh PC, Marschke P, Ricker D, et al. Patient-reported urinary continence and sexual function after anatomic radical prostatectomy. Urology 2000;55:58-61. http://dx.doi.org/10.1016/S00904295(99)00397-0

4. Moinzadeh A, Shunaigat AN, Libertino JA. Urinary incontinence after radical retropubic prostatectomy: the outcome of a surgical technique. BJU Int 2003;92:355-9. http://dx.doi.org/10.1046/i.1464410X.2003.04348.x

5. Lepor H, Kaci L, Xue X. Continence following radical retropubic prostatectomy using self-reporting instruments. J Urol 2004;171:1212-5. http://dx.doi.org/10.1097/01.ju.0000110631.81774.9c

6. Goluboff ET, Chang DT, Olsson CA, et al. Urodynamics and the etiology of post-prostatectomy incontinence: the initial Columbia experience. J Urol 1995;153(3 Pt 2):1034-7. http://dx.doi.org/10.1016/ S0022-5347(01)67629-8

7. Jonler $M$, Madsen FA, Rhodes PR, et al. A prospective study of quantification of urinary incontinence and quality of life in patients undergoing radical retropubic prostatectomy. Urology 1996;48:433-40. http:// dx.doi.org/10.1016/S0090-4295(96)00216-6

8. Donnellan SM, Duncan HJ, MacGregor RJ, et al. Prospective assessment of incontinence after radical retropubic prostatectomy: objective and subjective analysis. Urology 1997;49:225-30. http://dx.doi. org/10.1016/50090-4295(96)00451-7

9. Bates TS, Wright MP, Gillatt DA. Prevalence and impact of incontinence and impotence following total prostatectomy assessed anonymously by the ICS-male questionnaire. Eur Urol 1998;33:165-9. http:// dx.doi.org/10.1159/000019549

10. Nitti VW. Postprostatectomy incontinence. In Walsh PC, Retik AB, Vaughan ED, Wein AJ (eds): Campbell's Urology, 8th ed. Philadelphia, WB Saunders;2002:1053.

11. Chao R, Mayo ME. Incontinence after radical prostatectomy: detrusor or sphincter causes. J Urol 1995;154:16-8. http://dx.doi.org/10.1016/S0022-5347(01)67212-4

12. Gudziak MR, McGuire EJ, Gormley EA. Urodynamic assessment of urethral sphincter function in post-prostatectomy incontinence. J Urol 1996;156:1131-5. http://dx.doi.org/10.1016/S0022$5347(01) 65724-0$

13. Desautel MG, Kapoor R, Badlani GH. Sphincteric incontinence: the primary cause of post-prostatectomy incontinence in patients with prostate cancer. Neurourol Urodyn 1997;16:153-60. http://dx.doi. org/10.1002/(SICI) 1520-6777(1997) 16:3<153::AID-NAU4>3.0.C0;2-D

14. Ficazzola M, Nitti VW. The etiology of post-radical prostatectomy incontinence and correlation of symptoms with urodynamic findings. J Urol 1998;160:1317-20. http://dx.doi.org/10.1016/S0022$5347(01) 62525-4$

15. Winters JC, Appell RA, Rackley RR. Urodynamic findings in postprostatectomy incontinence. Neurourol Urodyn 1998;17:493-8. http://dx.doi.org/10.1002/(SICI) 1520-6777 (1998) 17:5<493::AIDNAU5 $>3.0 .00 ; 2-8$

16. Groutz A, Blaivas IG, Chaikin DC, et al. The pathophysiology of post-radical prostatectomy incontinence: a clinical and video urodynamic study. J Urol 2000;163:1767-70. http://dx.doi.org/10.1016/ S0022-5347(05)67538-6

17. Ward JF, Sebo TJ, Blute ML, et al. Salvage surgery for radiorecurrent prostate cancer: contemporary outcomes. J Urol 2005;173:1156-60. http://dx.doi.org/10.1097/01.ju.0000155534.54711.60 
Radomski

18. Zagars GK, von Eschenbach AC, Johnson DE, et al. Stage C adenocarcinoma of the prostate. Analysis of 551 patients treated with external beam radiation. Cancer 1987;60:1489-99. http://dx.doi. org/10.1002/1097-0142(19871001)60:7<1489::AlD-CNCR2820600715>3.0.C0;2-9

19. Benoit RM, Naslund MJ, Cohen JK. Complications after prostate brachytherapy in the Medicare population. Urology 2000;55:91-6. http://dx.doi.org/10.1016/S0090-4295(99)00122-3

20. Ahmed HU, Moore C, Emberton M. Minimally-invasive technologies in uro-oncology: the role of cryotherapy, HIFU and photodynamic therapy in whole gland and focal therapy of localized prostate cancer. Surg Oncol 2009;18:219-32. http://dx.doi.org/10.1016/i.suronc.2009.02.002

21. Herschorn S, Bruschini $\mathrm{H}$, Comiter $\mathrm{C}$, et al. Surgical treatment of stress incontinence in men. Neurourol Urodyn 2010;29:179-90. http://dx.doi.org/10.1002/nau.20844

22. Wyman JF, Choi SC, Harkins SW, et al. The urinary diary in evaluation of incontinent women: a test-retest analysis. Obstet Gynecol 1988;71 (6 Pt 1):812-7.

23. Schick $E$, Jolivet-Tremblay $M$, Dupont $C$, et al. Frequency-volume chart: the minimum number of days required to obtain reliable results. Neurourol Urodyn 2003;22:92-6. http://dx.doi.org/10.1002/ nau. 10079

24. Mouritsen L, Berild G, Hertz J. Comparison of different methods for quantification of urinary leakage in incontinent women. Neurourol Urodyn 1989;8:579-86. http://dx.doi.org/10.1002/nau.1930080604

25. Abrams P. Detrusor instability and bladder outlet obstruction. Neurourol Urodyn 1985;4:317-28. http:// dx.doi.org/10.1002/nau.1930040409

26. Thiel DD, Young PR, Broderick GA, et al. Do clinical or urodynamic parameters predict artificial urinary sphincter outcome in post-radical prostatectomy incontinence? Urology 2007;69:315-9. http://dx.doi. org/10.1016/j.urology.2006.10.026
27. Trigo-Rocha F, Gomes CM, Mitre Al, et al. A prospective study evaluating the efficacy of the artificial sphincter AMS 800 for the treatment of postradical prostatectomy urinary incontinence and the correlation between preoperative urodynamic and surgical outcomes. Urology 2008;71:85-9. http://dx.doi. org/10.1016/i.urology.2007.09.009

28. Lepor H, Kaci L. The impact of open radical retropubic prostatectomy on continence and lower urinary tract symptoms: a prospective assessment using validated self-administered outcome instruments. J Urol 2004;171:1216-9. hitp://dx.doi.org/10.1097/01.ju.0000113964.68020.a7

29. Galli S, Simonato A, Bozzola A, et al. Oncologic outcome and continence recovery after laparoscopic radical prostatectomy: 3 years' follow-up in a "second generation center." Eur Urol 2006;49:859-65. http://dx.doi.org/10.1016/j.eururo.2006.01.035

30. Colombo R, Naspro R, Salonia A, et al. Radical prostatectomy after previous prostate surgery: clinical and functional outcomes. J Urol 2006;176(6 Pt 1):2459-63. http://dx.doi.org/10.1016/i. juro.2006.07.140

Correspondence: Dr. Sidney B. Radomski, Toronto Western Hospital, Main Pavilion, 8th Floor Rm. 304, 399 Bathurst St., Toronto, ON M5T 2S8; sidney.radomski@uhn.ca 